\title{
INFLUÊNCIAS SOCIOCULTURAIS NA ESCOLARIDADE DE CONSCRITOS ${ }^{1}$
}

\section{Pesquisa avalia a influência da condição socioeconômico-cultural da família no desenvolvimento escolar de jovens e compara níveis de escolaridade de pais e filhos}

Em vários estudos populacionais e epidemiológicos a escolaridade dos pais tem sido levada em conta como fator preponderante na determinação das condições de nutrição e saúde da criança e do adolescente. À elevação do nível de escolaridade condiciona-se o posicionamento do indivíduo na sociedade. Acredita-se que, quanto mais alto for o grau de escolaridade e de conhecimento, maior será a possibilidade do exercício da cidadania (Parâmetros Curriculares, 1997) e, segundo Galazi ${ }^{2}$, da conquista de ascensão social. Uma boa formação também favorece a conquista de melhores condições de vida, incluindo uma boa saúde. Partindo deste princípio, desenvolvemos a pesquisa Saúde da criança: do hospital ao serviço militar, cuja segunda parte descrevemos neste artigo ${ }^{3}$. O acompanhamento de uma coorte (população) de recémnascidos de Ribeirão Preto, durante 18 anos, permitiu avaliar especificamente a relação escolaridade de pais, filhos e saúde. Isto foi possível devido a um atuante trabalho de pesquisa da pós-graduação em pediatria e à ampliação da discussão com a participação de educadores, numa perspectiva de trabalho transdisciplinar ${ }^{4}$.
Na literatura científica revista, não havia indicação da existência de estudos de coorte que tenham dirigido seus objetivos para avaliar es-

\section{OS AUTORES}

\section{Leris S. B. Haeffner}

Professora de Pediatria da Universidade Federal de Santa Maria, Rio Grande do Sul.

Maria Inês F. Miranda

Professora na Enfermagem da Universidade Federal de Rondônia.

Carlos H. F. Tavares

Professor de Pediatria na Universidade Federal de Alagoas.

\section{Marisa R. Barbieri}

Professora Doutora do Departamento de Psicologia e Educação e do Laboratório de Ensino de Ciências da Faculdade de Filosofia, Ciências e Letras de Ribeirão Preto da USP.

\section{Heloísa Bettiol}

Professora Doutora da Faculdade de Medicina de Ribeirão Preto da USP.

Marco Antônio Barbieri

Professor Titular da Faculdade de Medicina de Ribeirão Preto da USP.

E-mail: hbettiol@fmrp.usp.br

1. Este trabalho é parte do projeto de pesquisa Saúde da criança: do hospital ao serviço militar. Estudo epidemiológico-social longitudinal de uma coorte de recém-nascidos de parto hospitalar no período de 06/78 a 05/79 em Ribeirão Preto, que se realiza na Faculdade de Medicina de Ribeirão Preto, da Universidade de São Paulo, desde 1978. O projeto é financiado pela Fundação de Amparo à Pesquisa São Paulo - FAPESP.

2. GALAZI, J. M. Filho de pai sem instrução avança mais na escola que os outros. O Estado de S. Paulo. São Paulo, 17 de dezembro, 1997. A-10.

3. A primeira parte dos resultados da pesquisa pode ser encontrada em: MIRANDA, Maria I. F. et al. Transdisciplinaridade: o desafio de inovar. Comunicação \& Educação. São Paulo: CCA-ECA-USP/Moderna, n. 14, jan./abr. 1999. p. 33-41.

4. BARBIERI, M. R., et al. Nucleus for the study of children and adolescents. (Núcleo de estudo da criança e do adolescente.) Comunicação apresentada e publicada nos Anais da Biennale de l'éducation et de la formation. Paris: Sorbone 36, 1994. 
pecificamente a escolaridade dos sujeitos participantes. Mas o tema já despertava interesse, especialmente da imprensa. Vários artigos, em importantes jornais do país, observavam o aumento da escolaridade na população brasileira. Segundo os artigos, este quadro é resultado do movimento de democratização das relações entre o Estado e a sociedade, impulsionado a partir da década de $80^{5}$. Neste contexto, as diretrizes educacionais, traçadas pelos planos governamentais, elegeram a democratização da educação, nas suas dimensões de gestão participativa e ampliação das oportunidades educacionais, como seus eixos básicos ${ }^{6}$. Segundo dados da grande impensa, o acesso ao ensino fundamental no Brasil, no final da década de 80 , estava praticamente universalizado ${ }^{7}$.

Os dados coletados para o projeto $E s$ tudo epidemiológico-social, longitudinal da saúde da criança em três momentos: ao nascer, na idade escolar e aos 18 anos teve como princípio o desenvolvimento de um novo foco de análise, ampliando os até então apontados pela imprensa, como os já citados acima. O ponto básico de sustentação do projeto como um todo, desde o seu início com a pesquisa Saúde perinatal em Ribeirão Preto, foi o de procurar articular os determinantes biológicos do processo saúde-doença em um contexto social, tendo como hipótese que as causas sociais podem desencadear e transformar os fatores biológicos ${ }^{8}$.

A constatação de que os filhos que entraram na escola na década de 80 tiveram me- lhores oportunidades de acesso escolar do que seus pais levou à ampliação da pesquisa. Através da comparação da escolaridade dos conscritos pertencentes à coorte de recém-nascidos de Ribeirão Preto com a de seus pais, procurou-se comprovar a hipótese de que os filhos teriam superado o nível dos pais no que se refere à atividade escolar.

\section{METODOLOGIA E POPULAÇÃO DO ESTUDO}

Ribeirão Preto, no Estado de São Paulo, é conhecida como uma das mais ricas regiões do interior do Brasil, com população de $485 \mathrm{mil}$ habitantes (IBGE, dados estimados para 1996), renda anual percapita de US\$5.800,00 e economia baseada na agro-indústria. $\mathrm{O}$ setor educacional tem mais de 135 mil alunos, sendo 122.285 no ensino fundamental e médio e 13 mil universitários ${ }^{9}$.

Todos os nascimentos ocorridos na cidade de Ribeirão Preto no período de $1^{\circ}$ de junho de 1978 a 31 de maio de 1979 fizeram parte do projeto de pesquisa Saúde perinatal em Ribeirão Preto, que coletou dados de $98 \%$ do universo de nascidos vivos no período. Como se trata de um estudo de coorte, estas crianças foram reavaliadas na idade escolar e os meninos no serviço militar, já que o mesmo é obrigatório para todos os jovens.

Na última avaliação, feita à época da inscrição do serviço militar, foi possível veri-

\footnotetext{
5. CALDAS, S. Pesquisa do IBGE aponta melhora no ensino. O Estado de S. Paulo. São Paulo, 12 de novembro, 1997. GALAZI, J. M. Filho de pai sem instrução avança mais na escola que os outros. O Estado de S. Paulo. São Paulo, 17 de dezembro, 1997. p. A-10. SABOYA, A. L. Brasil tem infância de contraste. Jornal do Brasil. Rio de Janeiro, 18 de novembro, 1997, p. 4.

6. CABRAL NETO, A. Ampliação das oportunidades educacionais: realidade ou direito negado? Cadernos de Pesquisa. São Paulo, Fundação Carlos Chagas, n. 99, 1996. p. 46.

7. CASTRO, C. M. OLIVEIRA, J. K. Educação: por onde começar? Encontro sobre melhoria da gestão e da qualidade da educação básica no Brasil. Fortaleza: PNUD-SENEB/MEC, 1991. MELLO, G. N. Políticas públicas e educaçāo. Estudos Avançados. São Paulo: Instituto de Estudos Avançados da USP, n. 5, 1991. p. 7-14. RIBEIRO, S. C. A pedagogia de repetência. Estudos Avançados. São Paulo: Instituto de Estudos Avançados da USP, n. 5, 1991. p. 14-25.

8. BARBIERI, M. A. et al. Sauide perinatal em Ribeirão Preto, São Paulo, Brasil: a questão do método. Cadernos de Saúde Pública. Rio de Janeiro, n. 5, 1989. p. 377-387.

9. CODERP. Prefeitura Municipal de Ribeirão Preto. 1998.
} 
ficar as condições de vida destes meninos que estavam completando a escolaridade básica e o seu crescimento físico.

Foram localizados no serviço militar 2.847 conscritos dos 3.520 recém-nascidos do sexo masculino pertencentes à coorte e, destes, 1.336 foram entrevistados. Os dados foram obtidos das fichas do alistamento militar e das entrevistas. Não se obteve informação sobre a escolaridade de 9 conscritos (dado ausente na ficha de alistamento militar), de 381 pais e de 301 mães (o conscrito não soube informar), obtendo-se uma amostra com dados sobre a escolaridade de 2.838 conscritos, 955 pais e 1.035 mães.

As variáveis coletadas foram: escolaridade dos pais; escolaridade do conscrito no momento do alistamento; tipo de escola freqüentada pelo conscrito durante sua vida estudantil; turno que freqüentou no último ano que estudou ou que ainda freqüentava; se ainda estava estudando; e, para os que pararam de estudar, há quanto tempo pararam, e se o motivo havia sido a necessidade de trabalhar.

Para a escolaridade do conscrito, foi considerada a série que ele estava freqüentando ou a série concluída antes de parar de estudar. Para a escolaridade dos pais, considerou-se a série concluída informada pelos conscritos.

Se nenhum percalço ocorrer na vida estudantil de um aluno típico, ele inicia sua escolaridade com 7 anos de idade cronológica e com 17 anos está concluindo o ensino médio. Há, no entanto, a possibilidade de iniciar a escolaridade um pouco mais tarde. Em vista disto, a pesquisa considerou escolaridade ideal - isto é, a relação série/idade - para o entrevistado, na época do serviço militar, estar na segunda ou terceira série do ensino médio, ter ensino médio completo ou curso superior incompleto. Os casos que não se enquadraram nesta categorização foram considerados como distorção série/idade.

Em termos de comparação entre os conscritos e seus pais, o cálculo da média e mediana de escolaridade dos pais desconsiderou a escolaridade igual ou maior que o segundo ano do curso superior, visto que os conscritos ainda não tinham idade suficiente para ter esta escolaridade.

A classificação social seguiu o modelo descrito por Goldani ${ }^{10}$, levando em conta a divisão geoeconômica do território urbano de Ribeirão Preto, assim classificada: bairro pobre quando $70 \%$ ou mais dos chefes-defamília tinham rendimento inferior a cinco salários mínimos; bairro médio-baixo quando 45 a $70 \%$ dos chefes-de-família tinham rendimento inferior a cinco salários mínimos; bairros médio-alto quando 20 a $45 \%$ dos chefes-de-família tinham rendimento inferior a cinco salários mínimos e bairro rico quando menos de $20 \%$ dos chefes-de-família tinham rendimento inferior a cinco salários mínimos. Para melhor análise, foi feita classificação em dois grupos: pobre+médio-baixo $(\mathrm{P}) \mathrm{e}$ rico+médio-alto $(\mathrm{R})$.

\section{ESCOLARIDADE E CLASSIFICAÇÃO SOCIAL}

Dos 2.838 conscritos que informaram a escolaridade, $4(0,1 \%)$ eram analfabetos; 144 $(5,1 \%)$ tinham da primeira à quarta série do ensino fundamental; $1.049(37,0 \%)$ tinham da quinta à oitava série do ensino fundamental; 
$1.155(40,7 \%)$ tinham o ensino médio incompleto; 336 $(11,8 \%)$ tinham o ensino médio completo; e $150(5,3 \%)$ estavam no curso superior. $\mathrm{Na}$ divisão em classes geoeconômicas, 500 $(17,5 \%)$ conscritos pertenciam ao grupo $\mathrm{R}(163$ residentes em bairro rico e 337 em bairro médio-alto); $2.340(82,3 \%)$ ao grupo $\mathrm{P}$ (1.214 residentes em bairro médio-baixo e 1.126 em bairro pobre) e $7(0,2 \%)$ não foram classificados.

A figura 1 mostra a distribuição dos conscritos quanto à escolaridade e condição geoeconômica. Dos conscritos do grupo R, $82,2 \%$ (409/500) estavam no ensino médio e curso superior, enquanto $52,7 \%(1.230 / 2.340)$ do grupo P estavam na mesma situação. Nas séries iniciais os percentuais se inverteram, com maior percentual para o grupo $\mathrm{P}$, além de todos os analfabetos (4) estarem neste grupo $(\mathrm{p}<0,05)$. $\%$

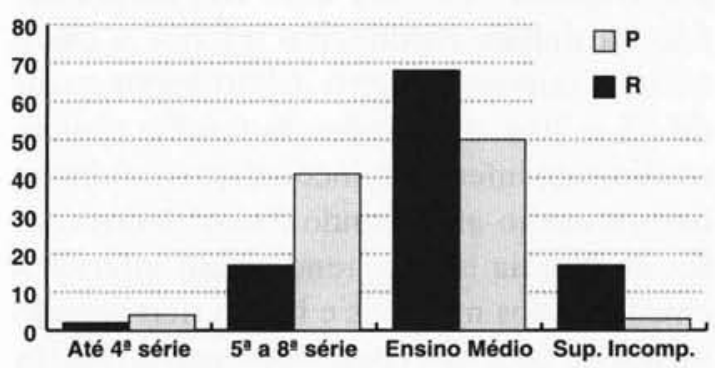

Figura 1 - Escolariedade dos conscritos segundo divisão geoeconômica da coorte de recém-nascidos de Ribeirão Preto 1978/1979. $x^{2}=220,9 P<0,05$.

A escolaridade ideal foi observada em $41,8 \%$ (1.186/2.838) dos conscritos. Verificouse que o percentual de conscritos do grupo $\mathrm{R}$ com escolaridade ideal, 51,8\% (259/500), é mais do que o dobro do percentual observado no grupo $\mathrm{P}, 24,9 \%$ (581/2.333). Observou-se também que $30,6 \%$ (153/500) do grupo R e apenas $12,9 \%(303 / 2.340)$ do grupo $\mathrm{P}$ tinham o ensino médio completo ou estavam no curso superior. Na segunda série do ensino médio encontraram-se 19,6\% (63/322) dos conscritos do grupo R, contra $32,7 \%$ (283/864) do grupo $\mathrm{P}(\mathrm{p}<0,05)$.
O tipo de escola freqüentada pelos conscritos mostra que os pertencentes aos grupos sociais mais altos também usam a escola pública. Constatou-se que $31,9 \%(82 / 257)$ dos jovens do grupo $\mathrm{R}$ estudaram exclusivamente na escola pública e, ao adicionarmos a este dado aqueles que freqüentaram em algum momento de sua vida estudantil a escola pública, verificamos que este percentual passa para $60,7 \%$ (156/257). Do grupo P, $85,2 \%$ (917/1.076) estudaram exclusivamente na escola pública e apenas $3,8 \%$ (41/1.076) freqüentaram somente escola privada.

A transferência de escola pública para privada e vice-versa ocorreu com maior freqüência no grupo R. Observou-se que 21,0\% (54/257) dos conscritos deste grupo passaram da escola pública para a escola privada, contra $7,8 \%$ (20/257) do grupo P que passaram da escola privada para a pública. Quanto ao turno freqüentado, $56,4 \%(145 / 257)$ dos conscritos pertencentes ao grupo $\mathrm{R}$ estudaram no turno diurno, e $67,1 \%$ (722/1.076) do grupo $\mathrm{P}$ freqüentaram o turno noturno.

A maioria dos conscritos ainda freqüentava a escola no momento da avaliação. No entanto, o percentual de permanência foi superior no grupo R, 80,5\% destes (207/257) ainda estavam na escola, enquanto no grupo $\mathrm{P}$, continuavam estudando apenas $57,5 \%$ (617/ 1.079). Foi observado, ainda, que, no grupo R, $74 \%$ (37/50) dos que concluíram o ensino médio continuavam estudando, enquanto entre os do grupo $\mathrm{P}$ apenas $30,2 \%$ (44/146) estavam na mesma situação. Em relação ao tempo de afastamento da escola, um pequeno número relatou o abandono há mais de 5 anos e, destes, todos pertenciam ao grupo $\mathrm{P}$. $\mathrm{O}$ maior percentual de abandono da escola, há apenas um ano, correspondia ao grupo R. A média de tempo de abandono da escola foi de 2,1 anos, com um desvio-padrão de 1,5 anos e variando de 1 a 9 anos. 
Observou-se também em que série o abandono ocorreu (figura 2). A média de séries concluídas pelos conscritos que não estavam mais estudando foi a sexta série do ensino fundamental. Pararam de estudar entre a quinta e oitava séries do ensino fundamental $39,5 \%$ (202/512) do conjunto dos conscritos; $22,7 \%$ (116/512) completaram o ensino médio; $15,0 \%$ (77/512) pararam nas primeiras quatro séries do ensino fundamental e $11,1 \%$ (57/512) não concluíram o ensino médio. Os conscritos do grupo $\mathrm{R}$ saíram da escola no ensino médio, enquanto os do grupo $\mathrm{P}$ saíram entre a quinta a oitava série do ensino fundamental. No grupo R, 37,8\% (14/ 37) dos conscritos que não estavam mais freqüentando a escola há um ano concluíram o ensino médio e no grupo P, 44,2\% (99/224).

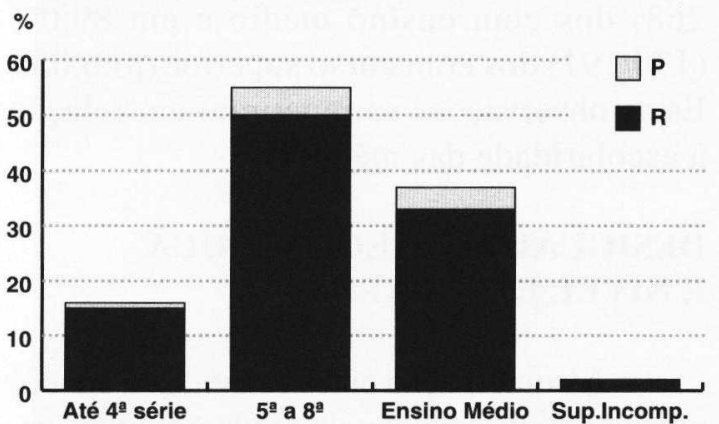

Figura 2 - Distribuição dos conscritos por série que parou de estudar e segundo o grupo geoeconômico da coorte de recém-nascidos de Ribeirão Preto 1978/1979.

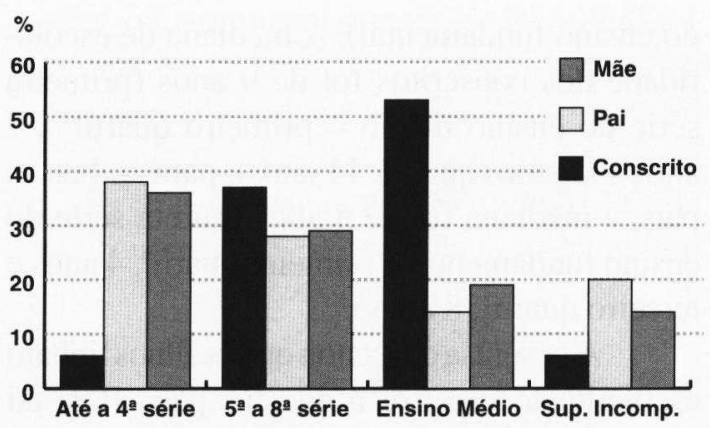

Figura 3 - Distribuição da escolariedade de pais e conscritos da coorte de recém-nascidos de Ribeirão Preto $1978 / 1979$.

\section{ESCOLARIDADE COMPARADA}

Foi comparada a escolaridade dos conscritos em relação à escolaridade de seus pais. $\mathrm{O}$ percentual de analfabetismo dos conscritos foi de $0,1 \%$, de seus pais foi de $2,2 \%$ e de suas mães de $4,2 \%$. É notória (figura 3) a relação inversa entre a sequiência de escolaridade dos conscritos e a de seus pais, isto é, há uma tendência de elevação da escolaridade dos conscritos até o ensino médio, por outro lado, percebe-se um movimento decrescente na escolaridade dos pais. Concluíram o ensino fundamental $60,6 \%$ (1.721/2.838) dos conscritos, 47,1\% (450/955) dos pais e 47,3\% (490/1.035) das mães $(\mathrm{P}<0,05)$. A média de escolaridade dos conscritos foi de 8,6 anos (primeira série do ensino médio), a dos pais, 6 anos e a das mães, 6,2 anos (sexta série

Tabela 1 - Distribuição dos pais quanto à escolaridade e número de filhos com o mesmo grau de escolaridade mas com uma ou mais série que seus pais

\begin{tabular}{|c|c|c|c|c|c|c|}
\hline \multirow{3}{*}{ Escolaridade } & \multicolumn{6}{|c|}{ Conscritos com uma ou mais séries que seus pais } \\
\hline & \multicolumn{3}{|c|}{ Pai } & \multicolumn{3}{|c|}{ Mãe } \\
\hline & NT & SS & $\%$ & NT & SS & $\%$ \\
\hline Até $4^{a}$ série & 41 & 11 & 26,8 & 49 & 26 & 53,1 \\
\hline $5^{\mathrm{a}}$ a $8^{\mathrm{a}}$ série & 256 & 177 & 69.1 & 286 & 188 & 65,7 \\
\hline Ensino Médio & 553 & 356 & 64,4 & 592 & 326 & 55,1 \\
\hline Superior Incompleto & 105 & 46 & 43,8 & 108 & 60 & 55,5 \\
\hline TOTAL & 955 & 590 & 61,8 & 1035 & 600 & 58,0 \\
\hline
\end{tabular}

NT = número total SS $=$ Conscritos com Série Superior a seus pais $\quad X^{2}=90,67 \mathrm{P}<0,05$ 
do ensino fundamental). A mediana de escolaridade dos conscritos foi de 9 anos (primeira série do ensino médio - primeiro quartil ", 7 anos e terceiro quartil, 11 anos); para ambos os pais, a mediana foi de 5 anos (quinta série do ensino fundamental - primeiro quartil, 4 anos $\mathrm{e}$ terceiro quartil, 8 anos).

A pesquisa constatou que os filhos tinham escolaridade superior à de seus pais. Para tal análise, considerou-se o filho que havia completado pelo menos uma série a mais que seus pais. Em comparação com os pais, $61,8 \%$ (590/ 955) estavam mais adiantados e comparando com as mães, $58,0 \%(600 / 1035)$. O fato se torna evidente a partir da quinta série do ensino fundamental e se mantém no ensino médio, tanto em relação ao pai como à mãe (tabela 1 ).

Houve também diferença significante $(\mathrm{p}<0,05)$ entre o percentual de conscritos que alcançaram o ensino médio e principalmente o curso superior, e o grau de escolaridade de seus pais (tabela 2).

Dos pais que tinham o ensino fundamental completo ou incompleto, $53,5 \%$ (336/ 628) dos filhos passaram para o ensino médio e $3,8 \%(24 / 628)$ passaram para o curso superior. Dos pais que tinham ensino médio completo ou incompleto, $69,1 \%(94 / 136)$ dos filhos estavam no ensino médio e 16,2\% (22/
136) já estavam no curso superior. Entre os que tinham curso superior completo ou incompleto, $64,4 \%$ (123/191) dos filhos estavam no ensino médio e 30,9\% (59/191) já estavam cursando a Universidade.

Além da mobilidade ascendente da escolaridade dos conscritos em relação a seus pais e da relação maior escolaridade dos filhos-nível maior de escolaridade dos pais, pôde-se verificar que a escolaridade ideal, isto é, sem distorção série/idade, também elevou-se proporcionalmente ao aumento da escolaridade dos pais. A escolaridade ideal foi observada em 38,6\% (139/360) dos filhos de pais que tinham até a quarta série do ensino fundamental; em $54,1 \%(145 / 268)$ dos que cursaram entre a quinta e a oitava série do ensino fundamental; em $69,1 \%$ (94/ 268) dos com ensino médio e em $89,0 \%$ $(170 / 191)$ dos com curso superior $(\mathrm{p}<0,05)$. Estas observações se repetiram em relação à escolaridade das mães.

\section{DESIGUALDADE ECONÔMICA E NÍVEL ESCOLAR}

A combinação entre estagnação econômica e má distribuição de renda é trágica, especialmente se consideramos os elevados ní-

Tabela 2 - Distribuição dos conscritos segundo seu grau de escolaridade em relação ao grau de escolaridade de seus pais

\begin{tabular}{|c|c|c|c|c|c|c|c|c|c|c|}
\hline \multirow{3}{*}{$\begin{array}{l}\text { Escolaridade } \\
\text { Conscrito }\end{array}$} & \multicolumn{8}{|c|}{ Escolaridade Pais } & \multirow{2}{*}{\multicolumn{2}{|c|}{ TOTAL }} \\
\hline & \multicolumn{2}{|c|}{ Até $4^{\mathrm{a}}$ série } & \multicolumn{2}{|c|}{$5^{\mathrm{a}}$ a $8^{\mathrm{a}}$ série } & \multicolumn{2}{|c|}{ Ensino Médio } & \multicolumn{2}{|c|}{ Superior } & & \\
\hline & $\mathbf{N}$ & $\%$ & $\mathbf{N}$ & $\%$ & $\mathbf{N}$ & $\%$ & $\mathbf{N}$ & $\%$ & $\mathbf{N}$ & $\%$ \\
\hline Até $4^{\mathrm{a}}$ série & 34 & 9,4 & 7 & 2,6 & 0 & 0 & 0 & 0 & 41 & 4,3 \\
\hline $5^{\mathrm{a}}$ a $8^{\mathrm{a}}$ série & 135 & 37,5 & 92 & 34,4 & 20 & 14,7 & 9 & 4,7 & 256 & 26,8 \\
\hline Ensino Médio & 178 & 49,5 & 158 & 58,9 & 94 & 69,1 & 123 & 64,4 & 553 & 57,9 \\
\hline Superior Inc. & 13 & 3,6 & 11 & 4,1 & 22 & 16,2 & 59 & 30,9 & 105 & 11,0 \\
\hline TOTAL & $\begin{array}{c}360 \\
(37,7 \%)\end{array}$ & 100 & $\begin{array}{c}268 \\
(28,1 \%)\end{array}$ & 100 & $\begin{array}{c}136 \\
(14,2 \%)\end{array}$ & 100 & $\begin{array}{c}191 \\
(20,0 \%)\end{array}$ & 100 & $\begin{array}{c}955 \\
(100 \%)\end{array}$ & 100 \\
\hline
\end{tabular}


veis de pobreza de um país como o Brasil. O crescimento do nível de renda, na década de 80 , foi modesto e a distribuição muito desigual. As conseqüências deste processo atingiram de forma bastante grave toda a população $\mathrm{e}$, especialmente, as crianças e adolescentes.

Os resultados dessa situação de pobreza têm efeito direto sobre a vida das crianças nos seus aspectos mais fundamentais: saúde, nutrição e educação. Em 1990, segundo dados do $\mathrm{IBGE}^{12}$, mais da metade da população infantojuvenil brasileira $(58,2 \%)$ era pobre. Em nossa amostra, coletada em Ribeirão Preto, $39,6 \%$ dos conscritos eram de extrato pobre.

Apesar das diferenças regionais, dados nacionais relativos a $1990^{13}$ mostraram que apenas $26,5 \%$ dos adolescentes de 17 anos possuíam oito ou mais anos de estudo. Na região Sudeste, $32,7 \%$ possuíam oito ou mais anos de estudo enquanto na região Nordeste, apenas $15,7 \%$.

Foi marcante e até inusitado o resultado deste estudo que constatou a elevação do grau de estudo dos conscritos, inclusive em relação à escolaridade dos seus pais e mães. Este resultado, embora alentador, não significa que o problema da educação tenha sido sanado. Um percentual importante $(39,4 \%)$ dos conscritos aos 18 anos idade em que deveriam estar concluindo ou já ter concluído o ensino médio - ainda não havia conseguido concluir o ensino fundamental.

Apesar de pequeno, consideramos importante esse salto no nível de escolaridade. No entanto, quando comparamos o índice apurado $(60,6 \%)$ ao de países mais pobres em termos de renda e com sistema escolar de 6 a 7 séries, como o México $(71,4 \%)$, Uruguai $(85,9 \%)$ e Venezuela $(73,1 \%)$, observamos que eles conseguem percentuais mais altos do que os nossos.
De acordo com os dados do IBGE de 1992, mesmo considerando que durante os anos 80 as famílias mais pobres experimentaram um maior aumento relativo na taxa de escolarização de seus filhos, em 1990 o nível de renda familiar continuava a ser um dos principais fatores de discriminação no acesso à educação. Isto também pôde ser verificado neste estudo. A escolaridade dos conscritos do grupo $\mathbf{R}$ (rica + média-alta) mostrou-se superior aos do grupo $\mathbf{P}$ (pobre + média-baixa).

$\mathrm{O}$ analfabetismo, situação pouco admissível às portas do terceiro milênio, ainda atinge um percentual de $20 \%$ dos brasileiros com 15 anos ou mais de idade. $\mathrm{Na}$ região Sudeste este percentual é de 12,3\% e, no Nordeste, o índice atinge $37,6 \%$, segundo dados do IBGE de 1995/1996 ${ }^{14}$. A amostra estudada em Ribeirão Preto, comparando-se a esses dados, revelou baixo índice de analfabetismo tanto entre os conscritos como entre seus pais e mães.

As pessoas do sexo feminino parecem ainda, na década de 90 , ter menor oportunidade de chegar à escola do que as do sexo masculino. Tal afirmação é confirmada pelos dados do IBGE de 1992 que apontaram um percentual de analfabetismo de 18,3\% para mulheres contra $17,9 \%$ para homens. Esta mesma relação também foi observada no analfabetismo dos pais e das mães dos conscritos deste estudo, embora com percentuais bem inferiores. Ressalta-se no entanto que, no Brasil, embora as mulheres continuem com maior taxa de analfabetismo, as que conseguem estudar vêm alcançando, nos últimos anos, maior nível de escolaridade do que os homens. 


\section{ESCOLA PÚBLICA VERSUS ESCOLA PRIVADA}

A diferença no percentual de uso das escolas pública e privada nas diferentes divisões econômicas da população evidencia a procura do grupo mais rico por escolas privadas, na tentativa de conseguir melhores condições de aprendizagem e, assim, ultrapassar as barreiras existentes no próprio sistema educacional brasileiro para chegar ao curso superior.

A mudança da escola pública para a escola privada é a que ocorre com maior frequiência, o que também deve estar relacionado com a preocupação com a qualidade do ensino, especialmente na época de preparação para o vestibular. Brandão ${ }^{15}$ descreveu que a forma como se processa a absorção do aluno pelo sistema educacional é o principal mecanismo de seleção e de exclusão. Para Dias, "os alunos de classes populares tendem a ser absorvidos por escolas típicas de classes populares, enquanto que alunos de classes não-populares são absorvidos por escolas próprias de seu grupo social"16. No entanto, é necessário ressaltar a importância da escola pública na vida estudantil de todas as camadas sociais. Mesmo no grupo $\mathrm{R}$ houve um percentual de $60,7 \%$ que, em algum momento, passou por ela.

As condições econômicas influenciam sobremaneira o uso do turno diurno ou noturno na escola. Um dos motivos que levam à opção pelo curso noturno, no caso de nossa pesquisa, é a necessidade dos conscritos do grupo $\mathrm{P}$ de trabalharem durante o dia, já que pertencem à classe menos favorecida. Outro motivo a ser considerado é que a escola pública estabelece idades para freqüência durante o dia. Como os jovens pesquisados tinham mais de 17 anos, provavelmente só conseguiam vagas para o turno noturno. Além disso, muitas escolas criam mais de dois turnos com o objetivo de ampliar o número de vagas (IBGE, 1992). Por falta de vaga, $\mathrm{o}$ aluno acaba estudando à noite.

\section{ACESSO NÃO DEMOCRATIZADO}

Com 18 anos de idade, mais de 50\% da amostra de ambos os grupos sociais ainda freqüentavam a escola. No entanto, a maior taxa corresponde à classe mais favorecida. Isso leva a uma reflexão sobre a democratização do acesso à escola.

É importante não só igualar as possibilidades de acesso, como também adequar essa oferta às aspirações de aprendizagem das populações, principalmente as excluídas, através de um ensino que mobilize e favoreça a permanência do aluno na escola. A evasão escolar significa não apenas o afastamento imediato do aluno, mas, a longo prazo, a restrição de uma efetiva participação na comunidade e na sociedade. Resultando em maior desigualdade, a um alto custo social ${ }^{17}$.

Diversos fatores contam para essa não permanência na escola, especialmente no ensino médio. A repetência escolar é um deles, mas a necessidade de trabalhar para aumentar a renda familiar, considerado o maior fator exógeno que levaria à evasão escolar, também tem sido muito enfatizada. Este fator no entanto não foi comprovado neste estudo, pois somente $13,2 \%$ dos conscritos que deixaram de estudar o fizeram para trabalhar.

15. BRANDĀO, Z., BAETA, A. B., ROCHA, A. D. C. Evasão e repetência no Brasil: a escola em questão. Rio de Janeiro: Achiamé, 1983.

16. DIAS, Maria Tereza Ramos. Desigualdades sociais e oportunidade educacional: a produção do fracasso. Rio de Janeiro: luperj. 1979. (Dissertação de Mestrado,)

17. IBGE. Crianças e adolescente... op. cit. p.1-159.

18. RIBEIRO, S. C. A pedagogia de repetência. Estudos Avançados. São Paulo: Instituto de Estudos Avançados da USP, n. 5. 1991. p. 14-25. 
Provavelmente, a repetência, a falta de estímulos do próprio sistema educacional e, finalmente, a falta de perspectivas de ascensão social em função da carreira escolar - já que neste país as oportunidades não são igualitárias e os que dependem de escola pública nem sempre têm as mesmas chances - sejam fatores determinantes para a não permanência na escola. Isto tudo mostra a necessidade de uma reformulação no sistema de ensino brasileiro ${ }^{18}$.

É evidente a importância de se definir políticas específicas, voltadas para a manutenção do aluno no sistema escolar, mais ainda do que simplesmente preocupar-se com a expansão quantitativa da oferta.

O maior avanço detectado no estudo realizado pelo IBGE e pelo Unicef, Indicadores sobre criança e adolescência, Brasil 91-96, foi quanto à escolaridade. Na faixa de 10 a 14 anos, o índice cresceu de $84,2 \%$ para $89,8 \%$. Mas o aumento do número de crianças nas escolas foi prejudicado pelos altos índices de evasão de repetência escolar. "É importante colocar a criança na escola, mas é igualmente importante mantê-las lá"19.

A taxa de evasão escolar, considerada entre os conscritos que não concluíram o ensino médio e não estavam mais freqüentando a escola, foi de $29,3 \%$. A taxa média de evasão escolar na década de 1978/88, no Brasil, foi maior na primeira e quinta séries do ensino fundamental (26\% e $23 \%$, respectivamente) do que nas demais séries. Neste aspecto, houve diferenças regionais importantes: no Nordeste, de $41 \%$ e no Sudeste, de $11 \%$.

Importante ressaltar que o período crítico para o abandono da escola são as últimas séries do ensino fundamental. Os conscritos que abandonaram a escola conseguiram concluir em média a sexta série do ensino funda- mental, diferentemente da média nacional de abandono que é de 3,7 séries. Os dados do PNAD-97 mostraram que $29 \%$ da população brasileira de 7 a 14 anos abandonam a escola antes de chegar à quinta série, desempenho idêntico ao do Paraguai, informa o Unicef.

O sistema educacional estabelece a idade de 7 anos para início da escolarização e isto define uma correspondência entre série/idade na vida escolar. No entanto, várias causas contribuem para a inadequação série/idade, entre elas a entrada tardia na escola e a repetência.

A taxa de $58,2 \%$ de distorção série/idade na faixa dos 14 anos, observada neste estudo restrito a Ribeirão Preto, embora elevada, é menor do que a taxa brasileira $(80 \%)$, a da região Nordeste $(92 \%)$ e a taxa da própria região Sudeste $(76 \%)$. Constatou-se a influência do nível de escolaridade dos pais nos níveis de distorção série/idade dos conscritos, já que não houve distorção entre $89,4 \%$ daqueles cujos pais tinham curso superior completo.

\section{INFLUÊNCIAS DA ESCOLARIDADE DOS PAIS}

A escolaridade dos pais, pelo que a pesquisa apontou, influencia sobremaneira a escolaridade dos filhos. Os filhos de pais com menor escolaridade têm mais dificuldade em seguir os estudos. Embora a escolaridade dos conscritos tenha melhorado em relação à escolaridade de seus pais - entre os níveis fundamental, médio e superior -, as barreiras não foram vencidas.

Estudar a escolaridade dos jovens conscritos e compará-la com a escolaridade de seus pais é uma forma de contribuir para a compreensão da complexidade que abrange as 
questões de políticas sociais no Brasil. Ouvese, hoje, o discurso de valorização do ensino fundamental em detrimento do ensino superior. No entanto, a valorização deveria se dar nos três níveis, pois os professores do ensino fundamental são formados pelos ensinos médio e superior.

A média de séries concluídas por jovens de 18 anos, em Ribeirão Preto, foi duas vezes maior que a brasileira conforme o estudo apurou e, além disso, a média de escolaridade (séries alcançadas na escola) dos filhos foi superior a de seus pais. Isto mostra que estes jovens tiveram melhores oportunidades de acesso à escola. Contudo, o número relativamente alto dos que ainda não tinham concluído o ensino fundamental comprova a dificuldade de permanência na escola, pelo menos até a conclusão desta fase. Já a evasão escolar em função da necessidade de trabalhar não foi confirmada neste estudo, embora seja um dos motivos mais recorrentes em pesquisas nacionais.

Resumo: $\mathrm{O}$ artigo descreve uma pesquisa desenvolvida pelos autores, em Ribeirão Preto, com o objetivo de comparar a escolaridade dos pais e dos conscritos pertencentes à coorte (população) de recém-nascidos na cidade entre 1978/1979 e de avaliar a relação da condição socioeconômico-cultural das familias no desenvolvimento escolar dos filhos. Dos meninos da coorte, 2.847 foram localizados no serviço militar e 1.336 foram entrevistados. Observou-se que o ensino fundamental foi concluído por $60,6 \%$ dos conscritos e por $47,1 \%$ dos pais. O grupo classificado como classe pobre/média baixa, nomeado de $\mathrm{P}$ pela pesquisa, apresentou menor escolaridade, mais utilização da escola pública e do turno noturno. Os autores concluíram que os fiIhos alcançaram nivel de escolaridade superior ao de seus pais $(61,8 \%)$ e mães $(58,0 \%)$. Também foi constatado que o acesso à escola melhorou. 0 problema da evasão escolar, no entanto, continua sério. Mas o fator trabalho não é o único, nem o mais expressivo responsável por este abandono.

Palavras-chave: conscritos, pais, coorte, escolaridade, evasão escolar, Ribeirão Preto, saúde
Vimos, por fim, que as condições socioeconômico-culturais das famílias exercem importante influência no grau de escolaridade dos filhos, bem como na sua permanência na escola. Condições que também são fundamentais para a conclusão da carreira escolar, na idade compatível com as normas do sistema educacional.

O mais importante é que pudemos comprovar cientificamente fatos empiricamente registrados e discutidos na imprensa $\mathrm{e}$ na sociedade como um todo. Esta pode ser uma boa contribuição não apenas para a discussão do tema mas, fundamentalmente, para a mobilização em busca de soluções.

Pesquisas como esta, muitas vezes, comprovam o óbvio. Valem não pela novidade ou pela descoberta. Valem pela ação de cidadania. Ou seja, pelo rompimento com o silêncio cômodo e conformador que em nada ajuda na construção de uma sociedade mais digna e justa.

Abstract. The article describes a survey carried out by the authors, in Ribeirão Preto, aiming at comparing the parent schooling levels of the recruits (conscritos) belonging to the cohort (population) of the newly borns between 1978/1979 and to evaluate the relation between the families' socioeconomic and cultural condition and their kid's development in school. Among the cohort boys, 2.847 were located in the military service and 1.336 were interviewed. It was noticed that while $60.6 \%$ of the recruits concluded elementary education, $47.1 \%$ of the parents had. The group classified as coming from the poor/low midclasses, denominated by the survey as $P$, presented the lower schooling levels, the greater use of public night schools. The authors concluded that the kids reached higher schooling levels than their fathers $(61.8 \%)$ and mothers $(58,0 \%)$. It was also noticed that access to school improved. The dropout problem, however, continued being a serious matter. However, the work factor is not the only one, nor the most expressive factor responsible for such dropout levels.

Key words: recruits, parents, cohort, schooling, school dropout, Ribeirão Preto, health 